\title{
Engineering Graduate Students' Salient Identities as Predictors of Perceived Task Difficulty
}

\section{Mr. Derrick James Satterfield, University of Nevada, Reno}

Derrick Satterfield is a Ph.D. student in Engineering Education and Chemical Engineering at the University of Nevada, Reno. He graduated from the University of Nevada, Reno in May 2017, and plans to pursue a career in academia in the future. His research interests are in graduate student attrition rates within academia, engineering identity development and the factors that influence decision making on persistence.

\section{Ms. Marissa A. Tsugawa, University of Nevada, Reno}

Marissa Tsugawa is a graduate research assistant studying at the University of Nevada, Reno in the PRiDE Research Group. She is currently working towards a Ph.D. in Engineering Education. She expects to graduate May of 2019. Her research interests include student development of identity and motivation in graduate engineering environments and understanding creativity in engineering design processes.

\section{Heather Perkins, North Carolina State University}

Heather entered the Applied Social and Community Psychology program in the fall of 2014, after completing her Bachelor of Science in Psychology from the University of Cincinnati. She has participated in various research projects examining the interaction between stereotypes and science interest and confidence, their influence upon womens' performance in school and the workplace, and their presence in the media and consequences for viewers. Her primary research interest is science identity, STEM education, and participation in online communities.

\section{Mr. Matthew Bahnson, North Carolina State University}

Matthew Bahnson is a doctoral student at North Carolina State University in Applied Social and Community Psychology. His research interests include engineering identity, diversity, bias, stereotypes, and STEM education. He works with Dr. Cheryl Cass at NCSU.

\section{Dr. Cheryl Cass, SAS Institute}

Cheryl Cass is a Senior Global Academic Program Manager in the Education Division at SAS Institute. She also holds a position as Adjunct Associate Professor in the Department of Materials Science and Engineering at North Carolina State University where she spent more than seven years as a teaching professor and Director of Undergraduate Programs.

\section{Dr. Adam Kirn, University of Nevada, Reno}

Adam Kirn is an Assistant Professor of Engineering Education at University of Nevada, Reno. His research focuses on the interactions between engineering cultures, student motivation, and their learning experiences. His projects involve the study of student perceptions, beliefs and attitudes towards becoming engineers, their problem solving processes, and cultural fit. His education includes a B.S. in Biomedical Engineering from Rose-Hulman Institute of Technology, a M.S. in Bioengineering and Ph.D. in Engineering and Science Education from Clemson University. 


\title{
Engineering Graduate Students' Salient Identities as Predictors of Perceived Task Difficulty
}

\author{
D. Satterfield ${ }^{\mathrm{a}}$, M. Tsugawa ${ }^{\mathrm{a}}$, H. Perkins ${ }^{\mathrm{b}}$, M. Bahnson ${ }^{\mathrm{b}}$, C. Cass ${ }^{\mathrm{c}}$, and A. \\ Kirn ${ }^{a}$ \\ ${ }^{a}$ College of Engineering, University of Nevada, Reno, ${ }^{\mathrm{b}}$ Applied Social and \\ Community Psychology, North Carolina State University, ${ }^{\mathrm{c}}$ Department of \\ Materials Science and Engineering, North Carolina State University
}

\begin{abstract}
This research paper examines the relationship between engineering graduate students' salient identities and their perception of research task difficulty. Data analyzed in this paper is from a larger project examining graduate student experiences in the United States. We contacted 693 institutions, to measure engineering graduate students' salient identities while doing research tasks and their perception of difficulty of tasks such as reading journal articles, conducting research, and attending conferences via electronic survey. A linear regression was used to examine the relationship between task difficulty and salience of researcher, scientist, and engineering identities for 1,482 students. We also tested if this relationship was moderated by demographics such as gender identity and degree type. The linear regression model indicated that researcher identity salience was a significant predictor $(\beta=0.245 ; \mathrm{t}(1,479)=9.693 ; \mathrm{p}<0.05)$ of engineering graduate students' perceived task difficulty. Specifically, perceived difficulty decreased with the higher salience of one's researcher identity. These findings are supported in identity-based motivation literature which posits that as students leverage an applicable identity (i.e., researcher, scientist or engineer) when completing a task, their perception of task difficulty decreases.
\end{abstract}

\section{Introduction}

The purpose of this research paper was to explore how engineering graduate students' identities predict their perceptions of difficulty in completing research tasks.

Engineering graduate students (EGS) remain an understudied population in STEM and higher education research within the United States [1]. The limited body of work and the lack of understanding of the difficulties that students encounter allows for the propagation of negative student experiences in graduate education. Particularly, it was found that nearly $40 \%$ of engineering graduate students leave their engineering graduate program [2]. Factors that may contribute to such high attrition may include the increased likelihood of being diagnosed with a mental health issue [3], [4] and conflicting identities that undermine the values of academia (e.g., teacher and researcher [5] or simply being female [6]). These ongoing problems increase strain on both faculty and the graduate students who remain in their programs [7]-[9]. As engineering graduate education serves to produce leaders in innovative solutions to society's pressing issues [7], we need to develop a deeper understanding of EGS' experiences. 
This paper examines how identity salience influences engineering graduate students' (EGS) perceptions of research task difficulty. We chose to examine EGSs' experiences using an identity-based motivation lens. As such, we seek to answer the following question: Does salience of identities predict engineering graduate students' perception of difficulty of research tasks? We tested the following hypotheses to address our research question:

1. There is a positive relationship between salience of the researcher, scientist, and engineer identities and perceptions of task difficulty.

2. Demographic markers (e.g., gender identity) moderate the effect of salient identities on perceived task difficulty.

\section{Theoretical Framework: Identity-Based Motivation}

Identity-based motivation (IBM) is a theory "that explains when and in which situations people's identities motivate them to take action towards their own goals" [10]. Particularly, IBM explains how the identities that come to individuals' minds influence how individuals perceive task difficulty in different contexts to pursue goals [10]-[12]. For example, Oyserman and colleagues used IBM theory to examine how students' demographic identities (e.g., race/ethnicity, socioeconomic status, gender) matter when completing academic tasks [11]-[13]. These studies found that the identities that come to mind influenced students' perceptions of overcoming and valuing difficult tasks. Such research also showed that subtle environmental cues directly influenced which identities came to the students' minds and how students made sense of those identities within those environments. Within engineering graduate education, qualitative results indicated that a strong salient identity during task completion was important for increasing a student's motivation [14]. For this study, we focused on two IBM constructs: dynamic construction and perceived difficulty.

\section{Dynamic construction}

IBM assumes individuals' self-concepts (definition of the self) consists of a myriad identities and particular identities will come to mind (become salient) in different environments [10], [12], [15]. Particularly, how individuals identify in the moment depends on social cues and environmental contexts. For example, an engineering graduate student may identify as a parent, researcher, educator, and female. Within her engineering lab, she may identify as a researcher while performing experiments for her research project. However, her advisor might approach her with a woman in research award causing the engineering graduate student's female identification to become salient. As such, the identities that come to individuals' minds serve as a guide for how one should behave and act [12].

\section{Perceived Difficulty}

Perceived difficulty focuses on how individuals interpret overcoming and valuing difficult tasks based on the identities that come to mind in relation to their goals [11], [15]. When the identity that comes to mind aligns with individuals' goals, then tasks deemed as difficult have value in completing them. Further, the perception of difficulty depends on the identity that comes to mind within the context. For example, the female engineering graduate student mentioned above may 
feel that she can complete difficult tasks as doing so aligns with her goal of obtaining an engineering graduate degree.

\section{Methods}

As a part of a larger project examining graduate student experiences (NSF grant \#EHR-1535453 and 1535254), we distributed an electronic survey to engineering departments across the United States. The full survey employed measures to assess identity and motivation. This study explores the relationship between salient identities and perception of task difficulty from the identitybased motivation theory.

\section{Graduate Student Motivation and Identity Survey}

The Graduate Student Motivation and Identity Survey developed in previous work [16] measured how salient researcher, scientist, and engineer identities are while doing particular tasks and the perception of difficulty in doing such tasks. The tasks assessed include reading research publications, writing about research, conducting research, attending conferences, presenting research, and collaborating with other graduate students which emerged from our previous qualitative work [14]. For identity salience, the students reported on a 1 to 5 Likert-scale how much they disagree or agree with feeling like a researcher, scientist, and engineer while performing each of the listed tasks. An example of these items is shown in Fig. 1. Additionally, participants rated how difficult they considered each task. This item is shown in Fig. 2.

\section{To what extent do you disagree or agree with the following statements:}

When I read journal articles, I feel like a/an . . .

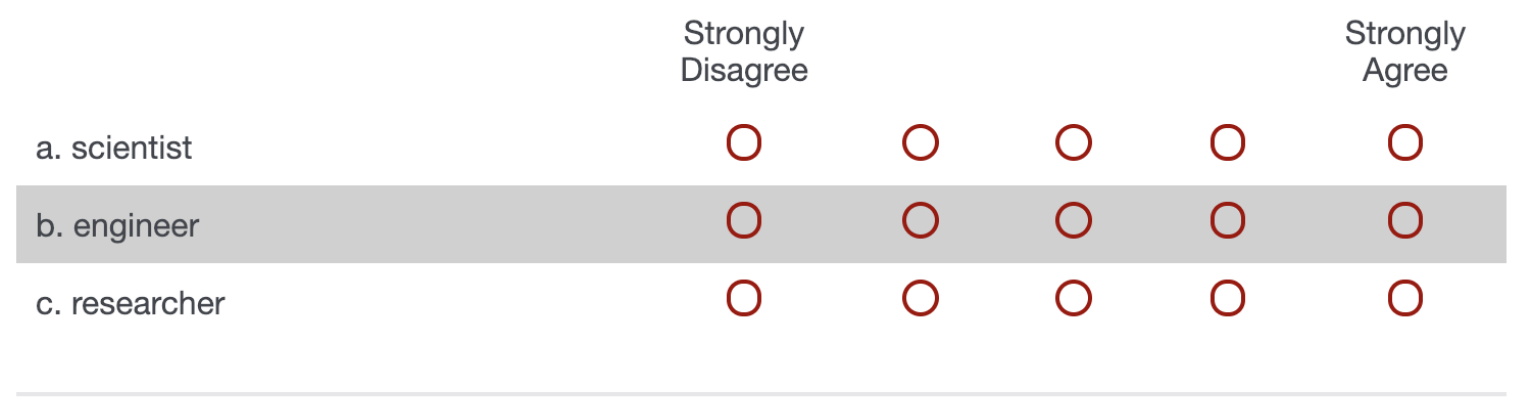

Fig. 1: Example of the items measuring identity salience while doing a task. 
To what extent do you disagree or agree with the following statements:

I consider the following tasks to be difficult ...

\begin{tabular}{|c|c|c|c|c|c|}
\hline & $\begin{array}{l}\text { Strongly } \\
\text { Disagree }\end{array}$ & & & & $\begin{array}{l}\text { Strongly } \\
\text { Agree }\end{array}$ \\
\hline Reading research publications & 0 & O & 0 & O & 0 \\
\hline Writing about my research & 0 & 0 & 0 & 0 & 0 \\
\hline Conducting research & 0 & O & 0 & O & 0 \\
\hline Attending conferences & 0 & 0 & 0 & 0 & 0 \\
\hline Presenting my research & 0 & O & 0 & O & 0 \\
\hline Attending classes & 0 & 0 & 0 & O & 0 \\
\hline Completing coursework/homework & 0 & 0 & 0 & 0 & 0 \\
\hline $\begin{array}{l}\text { Collaborating with other graduate students } \\
\text { (writing/research) }\end{array}$ & O & 0 & 0 & 0 & 0 \\
\hline Being a teaching assistant (TA) & 0 & 0 & 0 & O & 0 \\
\hline
\end{tabular}

Fig. 2: Perceived difficulty of tasks items.

To document demographics, we used an inclusive demographic scale developed for use in engineering education research [17]. These demographic items allow for open responses to how participants identify. For example, non-binary gender choices such as "agender" were available to choose. Also, students could choose more than one response per identity item such as gender identity (female and cisgender) and race/ethnicity (African American/Black and Caucasian/White). This allowed participants to indicate demographics that aligned with their own identification. We provide an example of such demographic questions in Fig. 3 the full set of demographic items can be found in Fernandez et al. [17]. We also utilized demographic questions related to the participants' graduate degree program or major.

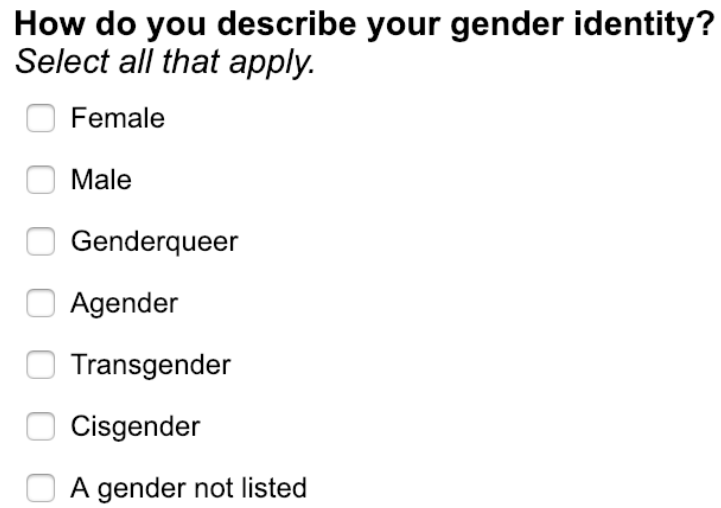

Fig. 3: Example of inclusive demographic item. 


\section{Survey Administration and Recruitment}

In the recruitment of participants, we attained a nationally representative sample by selecting engineering programs randomly from a national list of doctorate granting engineering programs $\left(\mathrm{n}_{\text {programs }}=1,382\right)$. From this list, programs were sampled using probability proportional to size sampling along criteria of state, program type, and program size (as measured by the number of PhD's awarded in the previous year) yielding 693 participating programs. We had $100 \%$ programmatic response rate, but we are unable to report on response rate at the student level as we were not given a full list of students for each of the programs.

\section{Population}

Approximately 2,300 engineering graduate students across the United States participated in our larger study measuring graduate motivation and identity. Participants who completed less than half of the survey were removed prior to analysis, leaving the working sample size at 1,754. Additionally, we removed remaining incomplete cases and outliers in relation to this study's variables. Incomplete cases consisted of participants that did not answer questions related to the identity-based motivation framework $\left(\mathrm{n}_{\text {missing }}=177\right)$. Further, outliers were removed from the sample to prevent our analysis results from being skewed by single points. We defined outliers as variable scores above or below three standard deviations away from the mean of each continuous variable $\left(\mathrm{n}_{\text {outliers }}=92\right)$. This resulted in a final sample size of 1,482 participants for this study.

Table 1 provides the gender identity, international status, and race/ethnicity breakdown of the sample by degree type to demonstrate the representation and potential generalizability of the results [18]. As participants had the opportunity to fill in multiple responses for gender and race/ethnicity, we combined smaller categories to increase their statistical power and prevent opportunities for re-identification. Considering gender, we grouped together those who identified as trans-, queer-, or agender or any combination of such into one category. We chose not to exclude these participants from the study as their experiences are often not accounted for or made visible by traditional gender studies (e.g., male/female studies). We also grouped together all participants who identified with more than one race/ethnicity into a multiracial category. Those who identified as only Black or African American; Hispanic, Latino/a/x, or Spanish origin; Middle Eastern or North African; and Native Hawaiian or Other Pacific Islander were grouped together into a single-identification ethnic minority category for statistical power. Further, we counted missing demographic responses as its own category as another study found significant differences between those who provide an answer and those who do not [19]. The majority of each demographic is represented by $\mathrm{PhD}$ students (76\%), Males (61\%), Domestic students (64\%), and White students (50\%). Considering the intersections of the demographics, Domestic White Male PhD students are the majority of the data $(21 \%)$ followed by Domestic White Female PhD students (13\%), Asian Male PhD students (11\%), and Domestic White Male Master's students (8\%). Overall, this demographic composition of our sample overrepresented non-male, domestic, and domestic White engineering graduate students when compared to the reported demographics from the National Science Foundation [20], [21]. Race/ethnicity information for international students and degree type ( $\mathrm{PhD}$ or Master's) were not reported in the 
National Science Foundation's Survey of Graduate Students and Postdoctorates in Science and Engineering [21].

Table 1: Sample gender identity, international status, and race/ethnicity distribution by degree type (PhD and Master's).

\begin{tabular}{|c|c|c|}
\hline Demographic & Master's & PhD \\
\hline \multicolumn{3}{|l|}{ Gender Identity } \\
\hline Male & 220 & 680 \\
\hline Female & 116 & 386 \\
\hline Trans-, Queer-, A-, + Genders & 9 & 18 \\
\hline Did Not Provide Response & 17 & 36 \\
\hline \multicolumn{3}{|l|}{ International Status } \\
\hline International & 113 & 398 \\
\hline Domestic & 239 & 705 \\
\hline Did Not Provide Response & 10 & 17 \\
\hline \multicolumn{3}{|l|}{ Race/Ethnicity } \\
\hline Asian & 112 & 301 \\
\hline Underrepresented Race/Ethnicity Group & 25 & 105 \\
\hline White & 180 & 561 \\
\hline Multiracial & 30 & 109 \\
\hline Did Not Provide Response & 15 & 44 \\
\hline Total & 362 & 1,120 \\
\hline
\end{tabular}

\section{Regression Model}

Our regression model consisted of three predictor variables and one outcome variable. We tested how salience of the researcher, scientist, and engineer identities predicted the perception of task difficulty. We chose the salient identity (researcher, scientist, and engineer) variables to predict task difficulty to test this relationship depicted by IBM theory [11], [15]. According to IBM, the more salient an identity is, the less difficulty is expected to be perceived for related tasks. As such, our standardized model (the intercept is zero) is as follows:

Task Difficulty $=b 1 *($ Researcher Identity $)+b 2 *($ Scientist Identity $)+b 3 *($ Engineer Identity $)$ 
The coefficients b1, b2, and b3 represent how much each predictor variable influences the outcome variable and is estimated using linear regression.

\section{Correlations}

To determine if each salient identity variable was distinct from one another, we performed a Pearson's correlation test [22]. The results showed a positive strong correlation between salient researcher (IBM_ResID) and scientist (IBM_SciID) identities ( $\mathrm{r}=0.493)$ as depicted as in Fig. 4. Further testing using the cor.test function in the R Statistical Software "stats" package [23] determined that this correlation is significant $(\mathrm{p}<0.05)$ suggesting these two variables may be theoretically indistinct [24]. As such, the scientist variable was dropped from our regression model for further testing.

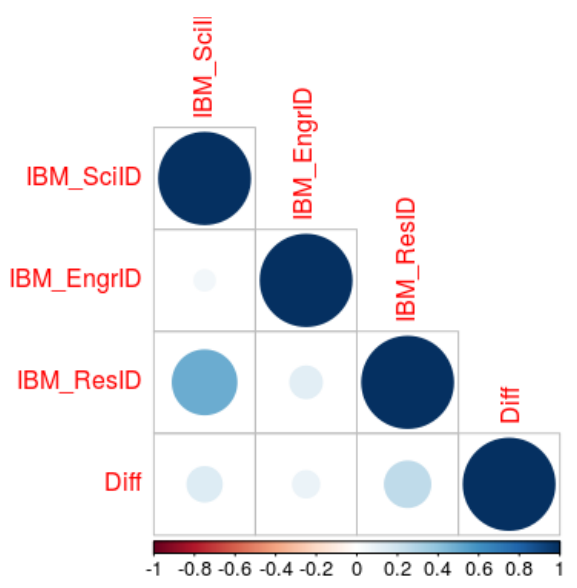

Fig. 4: Correlation plot between continuous variables where IBM_SciID is salient science identity, IBM_EngrID is salient engineer identity, IBM_ResID is salient researcher identity, and Diff_Res is perception of difficulty.

\section{Assumption Testing}

We used linear regression analysis to determine how salient identities (researcher, engineer, scientist) predict perceived task difficulty. A linear regression was chosen for its predictive power and strength in defining the relationship between multiple independent variables and single dependent variable [22]. All analysis was performed using R Statistical Software [23] and we tested for significance at a confidence level of $95 \%(a=0.05)$. Prior to analysis, we calculated the residuals from the model to determine if the model met the linear regression assumptions of normality and equal variances. We used the skewness and kurtosis criteria for normality where the distribution is considered normal for absolute values less than two and seven respectively [25]. The skewness (-0.050) and kurtosis (2.53) values (calculated using the "psych" package in $\mathrm{R}$ [26]) both fall within the acceptable range to be considered normal. We tested for equal variances using Levene's test (using the "car" package in R [27]) where if the test fails to reject the null hypothesis of the data has equal variances [28]. Our data failed to reject the null hypothesis $(\mathrm{p}>0.05)$ which indicated equal variances.

\section{Results}




\section{Regression}

Results indicated that salient researcher identity was a significant predictor of task difficulty $(\beta=$ $0.245 ; \mathrm{t}(1,479)=9.693 ; \mathrm{p}<0.05)$ meaning the more salient the researcher identity, the less difficult tasks are perceived to be. Salient engineering identity also significantly predicted task difficulty $(\beta=0.056 ; \mathrm{t}(1,479)=2.196 ; \mathrm{p}<0.05)$, however, this variable was 5 times less influential in predicting task difficulty. This model explained a significant portion of the variance $\left(\mathrm{R}^{2}=0.07 ; \mathrm{F}(2,1,479)=52.84 ; \mathrm{p}<0.05\right)$. Table 2 shows the model summary including the estimated coefficients $(\beta)$, standard error, t-value, $p$-value, and level of significance.

Table 2: Regression summary of the standardized model predicting task difficulty.

\begin{tabular}{llllll}
\hline Variable & $\boldsymbol{\beta}$ & Std. Error & t value & p-value & Level of Significance \\
\hline Intercept & 0 & 0.025 & 0.000 & 1.000 & \\
Researcher Identity & 0.245 & 0.025 & 9.693 & $<2 \mathrm{E}-16$ & $* * *$ \\
Engineering Identity & 0.056 & 0.05 & 2.196 & 0.028 & $*$ \\
\hline
\end{tabular}

\section{Moderators}

To determine if salient researcher identity has different effects for different groups, we further tested its relationship with perceived difficulty using demographics as moderators as shown in Fig. 5. Particularly, we tested degree type ( $\mathrm{PhD}$ or Masters), gender identity, race/ethnicity category, and international status as moderators of salient researcher identity on perceived difficulty. Across these models, the only significant interaction occurred between the demographic degree type and salient researcher identity to predict perceived difficulty ( $\beta=$ $0.171, t=2.971, p<0.05)$. This result indicated that the effect of salient researcher identity is moderated by what degree the participant was pursuing in predicting the task difficulty. A summary of the regression results is shown in Table 3. Further, post hoc analysis showed that those in $\mathrm{PhD}$ programs had higher salient researcher identity $(\bar{x}=0.18)$ than those in Masters programs $(\bar{x}=-0.55)$. This result indicated that PhD students are more likely to have a salient researcher identity and perceived tasks as less difficult.

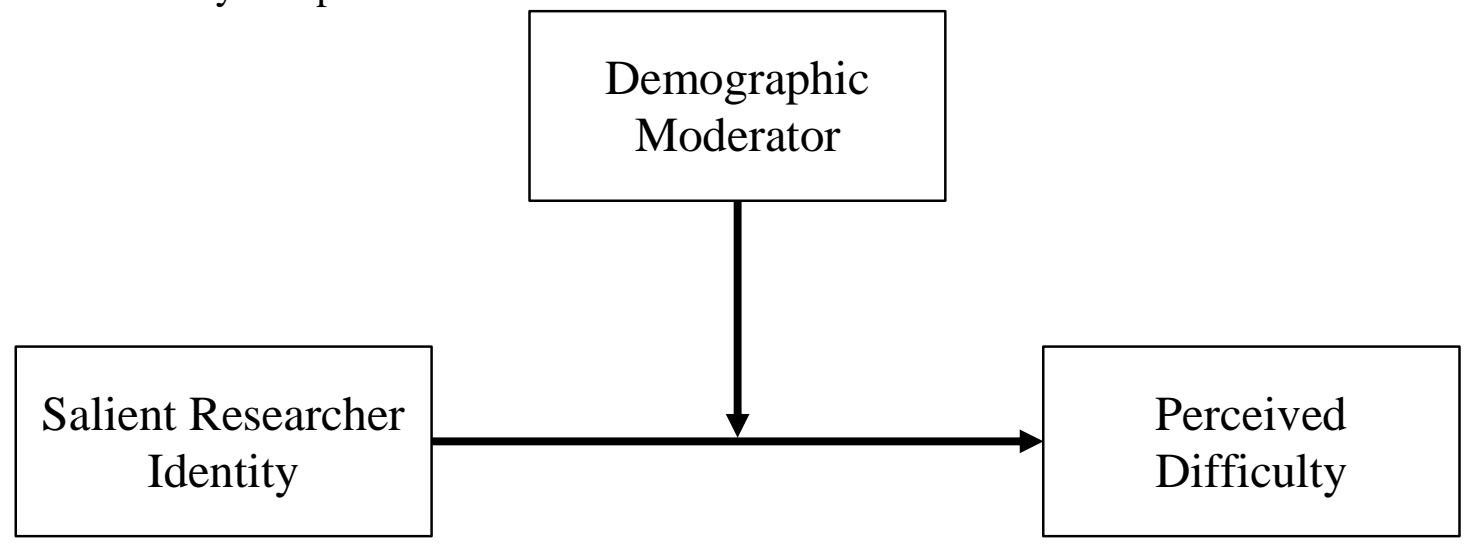

Fig. 5: Regression model of salient researcher identity on perceived difficulty with demographics as moderators. 
Table 3: Regression summary with degree type ( $\mathrm{PhD}$ and Masters) as moderator.

\begin{tabular}{llllll}
\hline Variable & $\boldsymbol{\beta}$ & Std. Error & $\mathbf{t}$ value & $\mathbf{p}$-value & Level of Significance \\
\hline Intercept & -0.029 & 0.057 & -0.512 & $<1$ & \\
Researcher Identity & 0.140 & 0.048 & 2.912 & $<0.05$ & $* *$ \\
Degree (PhD) & 0.009 & 0.064 & 0.134 & $<0.05$ & \\
$\begin{array}{l}\text { Researcher Identity } \\
\text { XDegree (PhD) }\end{array}$ & 0.171 & 0.057 & 2.971 & $<0.05$ & $* *$ \\
\hline
\end{tabular}

\section{Discussion}

\section{Identity salience as a predictor of task difficulty}

Our regression resulted in significant relationships between salient researcher and engineer identities and perceived difficulty supporting our first hypothesis. Although both salient identities were significant predictors of perceived difficulty, from the beta coefficients we determined that a salient researcher identity had a stronger relationship with the outcome variable than a salient engineering identity. This result demonstrates that when researcher identity is more salient during research tasks, the participants perceive their tasks as easier. Further, this result could be a product from the survey design as the tasks we assessed were related to doing research which could make the researcher identity more likely to come to mind. Prior to regression analyses, we saw a somewhat strong positive correlation between the salient researcher identity and perceived difficulty variables. Such correlation suggested that a relationship existed while the regression model quantified such relationship. These findings support the identity-based motivation (IBM) theory that when tasks align with salient identities, then the perceived difficulty of such tasks decrease [11], [13]. As such, the need for opportunities to develop a strong researcher identity is highlighted in our results in order to reduce the perception of difficulty in doing research tasks.

\section{Degree type as a moderator of task difficulty}

Degree type was the only demographic marker to serve as a moderator of researcher identity on perceived difficulty. This result supported our second hypothesis when considering degree type. Particularly, our regression model found that salient researcher identity was a stronger predictor of task difficulty in $\mathrm{PhD}$ students as opposed to Master's students. This result indicates that $\mathrm{PhD}$ students have a stronger researcher identity than the Master's students which decreases the level of difficulty in research tasks. This result could be a product of the structure of each degree type. Master's programs tend to have less research focused options while $\mathrm{PhD}$ programs are more research oriented. However, for both $\mathrm{PhD}$ and Master's students, having high salient researcher identity is important to perceive less difficulty in completing research tasks. Such result aligns 
with the identity-based motivation theory that when the salient identity makes sense in the context, tasks are perceived as less difficult [15].

This finding could indicate that when students lack a strong researcher identity, they find higher difficulty in completing research tasks, experience decreased motivation, and upon reaching major obstacles decide to depart. For those advisors who do not recognize this lack of an identity, this situation likely appears that the students do not have what it takes to succeed. This supports findings in doctoral education, where the culmination of negative experiences (students departing) was not due to a lack of skill or ability, but rather was from personal issues; conversely in the same study, faculty attributed over $50 \%$ of student attrition in doctoral programs to the student lacking skill or ability [29].

\section{Implications}

As research is an important aspect of completing a graduate degree [30], our results indicate the need for the intentional development of EGSs as researchers. One practice includes beginning researcher identity development at the undergraduate level through undergraduate research opportunities. Undergraduate students performing research tasks can increase their interest in research and are more likely to be recognized by other researchers as a researcher. These types of experiences can include collecting and analyzing data, co-authoring research papers, and presenting research which are important skills for graduate programs that many incoming graduate students lack [30]. Additionally, graduate students can serve as mentors to these undergraduate researchers to guide them in conducting research while graduate students benefit by learning how to mentor and receiving recognition as a researcher [31]. Such exposure can develop the researcher identity similarly to how engineering identity is developed [32]. Further, exposing research experiences to undergraduates can show them the research process and influence their consideration and decision to enroll in graduate school [33].

Another practice to develop EGSs' researcher identity throughout their graduate program includes knowing when EGSs need support or autonomy when conducting research tasks. Previous work found that a lack of advisor supervision was detrimental to graduate students' persistence in graduate programs [34], [35]. However, our previous work on EGSs [14] suggested that increasing EGSs' autonomy to conduct research tasks helped their identity development. Thus, finding the balance between too much and too little support is important [36]. To find this balance, advisors can recognize and assess their EGS' research abilities to know what skills they are struggling and thriving in. For example, consider an EGS writing up a conference paper. The advisor can recognize their EGS's writing skills (e.g., did the EGS write a conference paper before?) and then assess how much the advisor needs to assist in writing the conference paper. If the EGS has never written a conference paper, then the advisor will need to provide more support in the writing process such as inputting more feedback in earlier drafts. Further, the advisor can discuss with their EGS about the writing process to help develop their writing skills. If the EGS has written conference papers in the past, then the advisor can allow for more autonomy and provide comments and edits in later drafts. Graduate education is an 
opportunity for advisors to develop their graduate students at the individual level and calls for programs to be student-centered [7]. Thus, such individualized attention to know the level of autonomy each EGS needs is necessary to help them develop as researchers.

Other implications from our findings include designing graduate programs to support and take advantage of how EGSs view themselves in the present and future coming into their programs. For example, imagine an incoming EGS who strongly identifies as an engineer and expects the graduate experience to be immersed within solving engineer problems. That EGS may perceive doing research focused tasks as difficult as it does not align with their identity as an engineer. To alleviate such perceived difficulty, the advisor can communicate with the EGS about how they define being a graduate student in engineering. Once the advisor understands the EGS's point of view, the advisor can then design the research tasks to revolve around the EGS's goals and expectations. Considering the example, the advisor of the EGS who strongly identifies as an engineer can highlight the engineering behind research such as designing experiments. Further, the advisor can ask their EGS about how they view their future professional identity to understand the type of development their EGS needs [37], [38]. To understand what EGSs need, EGSs can complete Individualized Development Plans (IDPs) specifically designed for graduate students and available online [39]. These tools require graduate students to enter information such as career interests to determine what experiences and skills the student should gain. Advisors then can use IDPs to find opportunities, resources, and mentors that can develop EGS into their future professional identity [40].

\section{Conclusions}

To further contribute to the conversation surrounding graduate student experiences within engineering, this paper examined student's identity salience as a predictor of task difficulty in research related tasks (i.e. journal article writing, conducting research). Findings indicate that as a students' researcher, scientist, and engineering identities increase, their perceptions of task difficulty decreased. Furthermore, a students' researcher identity has the most predictive power and significance in determining perceived task difficulty.

\section{Acknowledgements}

This project was funded by the National Science Foundation (\#EHR-1535453 and 1535254). We would like to thank all the participants for taking the time to participate in our research and sharing their stories. We also thank all the members of the research team including Daniel Briggs, Jessica Chestnut, Amber Parker, and Rebecca Mills for their time and insights. 


\section{References}

[1] D. Satterfield, M. A. Tsugawa-Nieves, and A. Kirn, "WIP: Factors Affecting Graduate STEM Student Attrition Rates," presented at the Frontiers in Education, 2018.

[2] Council of Graduate Schools, "Ph.D. Completion Project: Program Completion and Attrition Data," 2007.

[3] K. Levecque, F. Anseel, A. De Beuckelaer, J. Van der Heyden, and L. Gisle, "Work organization and mental health problems in PhD students," Research Policy, vol. 46, no. 4, pp. 868-879, May 2017.

[4] P. Barreira, M. Basilico, and V. Bolotnyy, "Graduate student mental health: Lessons from American economics departments," 2018.

[5] C. L. Colbeck, "Professional identity development theory and doctoral education," New Directions for Teaching and Learning, vol. 2008, no. 113, pp. 9-16, 2008.

[6] M. W. Sallee, "Performing Masculinity: Considering gender in doctoral Student Socialization," The Journal of Higher Education, vol. 82, pp. 187-216, 2011.

[7] Committee on Revitalizing Graduate STEM Education for the 21st Century, Board on Higher Education and Workforce, Policy and Global Affairs, and National Academies of Sciences, Engineering, and Medicine, Graduate STEM education for the 21 st century. Washington, D.C.: National Academies Press, 2018.

[8] J. L. Lott, S. Gardner, and D. A. Powers, "Doctoral student attrition in the stem fields: an exploratory event history analysis," Journal of College Student Retention: Research, Theory \& Practice, vol. 11, no. 2, pp. 247-266, Aug. 2009.

[9] E. Crede and M. Borrego, "Learning in Graduate Engineering Research Groups of Various Sizes," J. Eng. Educ., vol. 101, no. 3, pp. 565-589, Jul. 2012.

[10] E. Horowitz, N. Sorensen, N. Yoder, and D. Oyserman, "Teachers can do it: Scalable identity-based motivation intervention in the classroom," Contemp. Educ. Psychol., vol. 54, pp. 12-28, Jul. 2018.

[11] O. Fisher and D. Oyserman, "Assessing interpretations of experienced ease and difficulty as motivational constructs.," Motiv. Sci., vol. 3, no. 2, pp. 133-163, 2017.

[12] D. Oyserman and M. Destin, "Identity-based motivation: Implications for intervention.," Couns. Psychol., vol. 38, no. 7, pp. 1001-1043, Oct. 2010.

[13] K. C. Elmore and D. Oyserman, "If 'we' can succeed, 'I' can too: Identity-based motivation and gender in the classroom.," Contemp. Educ. Psychol., vol. 37, no. 3, pp. 176-185, Jul. 2012.

[14] B. Miller, M. A. Tsugawa-Nieves, J. N. Chestnut, C. Cass, and A. Kirn, "The Influence of Perceived Identity Fit on Engineering Doctoral Student Motivation and Performance," in 2017 ASEE Annual Conference \& Exposition, 2017.

[15] D. Oyserman, "Not just any path: Implications of identity-based motivation for disparities in school outcomes," Econ. Educ. Rev., vol. 33, pp. 179-190, Apr. 2013.

[16] H. Perkins, M. Bahnson, M. A. Tsugawa-Nieves, A. Kirn, and C. Cass, "Development and Testing of an Instrument to Understand Engineering Doctoral Students' Identities and 
Motivations," presented at the 2018 ASEE Annual Conference \& Exposition, 2018.

[17] T. Fernandez, A. Godwin, J. Doyle, D. Verdín, H. Boone, A. Kirn, L. Benson, and G. Potvin, "More Comprehensive and Inclusive Approaches to Demographic Data Collection," in 2016 ASEE Annual Conference \& Exposition, 2016.

[18] A. L. Pawley, "Shifting the 'default': the case for making diversity the expected condition for engineering education and making whiteness and maleness visible," J. Eng. Educ., vol. 106, no. 4, pp. 531-533, Oct. 2017.

[19] N. Pearson, J. C. Major, A. Godwin, and A. Kirn, "Using Social Network Analysis to Study the Social Structures of Inclusion," presented at the 2018 ASEE Annual Conference \& Exposition, 2018.

[20] National Science Foundation, "Doctorate Recipients from U.S. Universities: 2016," Alexandria, VA, Special Report NSF 18-304, 2017.

[21] National Science Foundation, "Survey of Graduate Students and Postdoctorates in Science and Engineering," National Center for Science and Engineering Statistics, 2016.

[22] J. Cohen, P. Cohen, S. G. West, and L. S. Aiken, Applied Multiple Regression/Correlation Analysis for the Behavioral Sciences, 3rd Edition, 3rd ed. Routledge, 2003.

[23] R Core Team, R: A language and environment for statistical computing. Vienna, Austria: R Foundation for Statistical Computing, 2017.

[24] B. G. Tabachnick and L. S. Fidell, Using multivariate statistics, 5th ed. Boston: Pearson/Allyn \& Bacon, 2006.

[25] P. J. Curran, S. G. West, and J. F. Finch, "The robustness of test statistics to nonnormality and specification error in confirmatory factor analysis.," Psychol. Methods, vol. 1, no. 1, pp. 16-29, 1996.

[26] W. Revelle, psych: Procedures for Personality and Psychological Research. Evanston, Illinois, USA: Northwestern University, 2017.

[27] J. Fox, S. Weisberg, B. Price, D. Adler, D. Bates, G. Baud-Bovy, B. Bolker, S. Ellison, D. Firth, M. Friendly, G. Gorjanc, S. Graves, R. Heiberger, R. Laboissiere, M. Maechler, G. Monette, D. Murdoch, H. Nilsson, D. Ogle, B. Ripley, and R-Core, car: Companion to Applied Regression. CRAN, 2018.

[28] J. L. Gastwirth, Y. R. Gel, and W. Miao, "The Impact of Levene's Test of Equality of Variances on Statistical Theory and Practice," Stat. Sci., vol. 24, no. 3, pp. 343-360, Aug. 2009.

[29] S. K. Gardner, "Student and faculty attributions of attrition in high and low-completing doctoral programs in the United States," High. Educ., vol. 58, no. 1, pp. 97-112, Jul. 2009.

[30] S. W. Rogers and R. K. Goktas, "Exploring Engineering Graduate Student Research Proficiency with Student Surveys," J. Eng. Educ., vol. 99, no. 3, pp. 263-278, Jul. 2010.

[31] H. Perkins, M. Bahnson, M. A. Tsugawa-Nieves, A. Kirn, and C. Cass, "WIP: Influence of Laboratory Group Makeup on Recognition and Identity Development in the Engineering Graduate Student Population,” presented at the 2018 IEEE Frontiers in 
Education Conference (FIE), 2018.

[32] A. Godwin, G. Potvin, Z. Hazari, and R. Lock, "Identity, critical agency, and engineering: an affective model for predicting engineering as a career choice," J. Eng. Educ., vol. 105, no. 2, pp. 312-340, Apr. 2016.

[33] M. Borrego, D. B. Knight, K. Gibbs, and E. Crede, "Pursuing graduate study: factors underlying undergraduate engineering students' decisions," J. Eng. Educ., vol. 107, no. 1, pp. 140-163, Jan. 2018.

[34] C. Herman, "Obstacles to success: Doctoral student attrition in South Africa," Perspectives in Education, vol. 29, no. 3, pp. 40-52, 2011.

[35] S. Kyvik and T. B. Olsen, "Increasing completion rates in Norwegian doctoral training: multiple causes for efficiency improvements," Studies in Higher Education, vol. 39, no. 9, pp. 1668-1682, Oct. 2014.

[36] S. K. Gardner, “'What's too much and what's too little?': The process of becoming an independent researcher in doctoral education," J. Higher Educ., vol. 79, no. 3, pp. 326350, 2008.

[37] K. V. Bruss and M. Kopala, "Graduate school training in psychology: Its impact upon the development of professional identity.," Psychotherapy: Theory, Research, Practice, Training, vol. 30, no. 4, pp. 685-691, 1993.

[38] K. Ducheny, H. L. Alletzhauser, D. Crandell, and T. R. Schneider, "Graduate student professional development.," Professional Psychology: Research and Practice, vol. 28, no. 1, pp. 87-91, 1997.

[39] "Individual Development Plans," National Institute of General Medical Sciences, 2016. [Online]. Available:

https://www.nigms.nih.gov/training/strategicplanimplementationblueprint/pages/Individua 1DevelopmentPlans.aspx. [Accessed: 27-Nov-2018].

[40] C. G. P. Berdanier, A. Tally, S. E. Branch, B. Ahn, and M. F. Cox, "A Strategic Blueprint for the Alignment of Doctoral Competencies with Disciplinary Expectations*," International Journal of Engineering Education, vol. 32, pp. 1759-1773, 2016. 